\title{
Describing the Light: Attribution Theory as an Explanation of the Near-Death Experience
}

\author{
Max C. Norton, Ph.D. \\ California State University - Stanislaus \\ James M. Sahlman, Ph.D. \\ Angelo State University
}

ABSTRACT. Attribution theory - which states that by offering causal explanations, individuals attempt to answer questions of "why?" - focuses on how information is used to create causal inferences and answer causal ques. tions. The finding that near-death experiencers rarely describe unknown events, characters, or objects suggests that NDErs make attributions to an. swer why these experiences occurred. Examining various descriptions of NDEs demonstrates how attribution theory explains individuals descriptions of their NDEs.

This is the first of a three part study exploring the phenomenon of causal and semantic attribution in the near-death experience (NDE). The purposes of these studies are to review the nature and function of attribution in the causal schema of the NDE, to examine the relationship between causal attribution and the belief system of the experiencer (NDEr) as revealed in the verbal accounts of NDEs, and to study the influence of causal attribution on the aftereffects of the NDE.

Previous studies have analyzed the factors underlying the NDE principally from the examination of anecdotal accounts (Gabbard and

Max C. Norton, Ph.D., is Professor Emeritus of Communication Disorders at California State University, Stanislaus, in Turlock, CA; and James M. Sahlman, Ph.D., is Assistant Professor of Communications, Drama, and Journalism at Angelo State University in San Angelo, TX. Reprint requests should be addressed to Dr. Norton at 5766 Stoddard Road, Modesto, CA 95356-9753. 
Twemlow, 1991; Irwin and Bramwell, 1988; Ross and Pollio, 1991; Sutherland, 1990). To date, no theory-based research has been directed toward the analysis of the causal elements. Some researchers have discussed a variety of paradigms (for example, Roberts and Owen, 1988), but these perspectives have not resulted in confirma. tory investigations. We propose to approach the study of the factors underlying the NDE through the application of models of semantic and causal attribution.

An attribution is the assignment of single or multiple causes for behavior. Harold Kelley (1973) explained:

Attribution theory is a theory about how people make causal explanations, about how they answer questions beginning with "why?" It deals with the information they use in making causal inferences, and with what they do with this information to answer causal questions. (p. 107)

Attributions are assigned as a result of either social or self perceptions. Of these two perceptual processes, it is self perception that we believe is relevant to the NDE. Kelley (1973) further explained that these perceptual processes are related to one's psychological epistemology: "This has to do with the processes by which man 'knows' his world and, more importantly, knows that he knows, that is, has a sense that his beliefs and judgments are veridical" (p. 107).

\section{Subjective Validity of the Near-Death Experience}

The phenomenon of subjective validity will be examined further in the third part of this study of the attributions of NDEs. We will, however, review the concept in the following section because of its relevance to the types of attributions considered in this study.

According to Kelley (1973), attribution validity deals with a particular aspect of self-knowledge. As an NDE cannot be verified by second party observation, it is a subjective phenomenon. Validity is established on the basis of an examination of one's self-knowledge. How then does the NDEr know that his or her perceptions, judgments, and evaluations are correct or true?

Kelly (1973) has suggested that the question can be answered when a person can confidently "make an entity attribution for a perception, judgment, or valuation" (p. 112). 
I know that my response to a particular stimulus is a valid one if (a) my response is associated distinctively with the stimulus; (b) my response is similar to those made by other persons to the same stimulus (there is consensus), and (c) my response is consistent over time - on successive exposures to the stimulus and as I interact with it by means of different sensory and conceptual modalities. (p. 112)

It can be readily seen that attributions associated with transpersonal experiences are not equivalent to those found in prior life ex. periences. However, the fact that the attributions found in NDEs are closely associated with the elements in the NDErs' prior lives provide the basis for establishing NDErs' confidence in the validity of their experiences. Craig Lundahi and Harold Widdison (1993) provided some support for this argument. In reviewing the social statuses of NDErs in the "City of Light," they described social activities as closely paralleling those found on earth, such as preparing for future events, gaining knowledge, assisting others, teaching, developing musical skills, researching family records, and performing routine and major tasks. We contend that these represent a continuity of earthly activities and values and would therefore provide validation of the NDErs' belief in eternal life. In the following discussion, we will outline the rationale for the establishment of subjective validity of the NDE.

First, confidence in the validity of an experience is reinforced through the sharing of testimonies with others who have had similar experiences. Consensus is the affirmation of the validity of observation by others who have experienced the same phenomenon. "Consensus has been shown in many experiments to afford a basis for confidence in one's judgment" (Kelley, 1973, p. 112). Second, temporal consistency, the repetition of an experience over a period of time, contributes to the subjective validity of the NDE. This is because events that are substantiated over a period of time provide confirmation of and confidence in one's attributional judgment. However, the study of NDEs through repeated observation is not possible.

Third, the extent to which an effect (response) can be associated distinctively with a specific stimulus is a critical test of subjective validity. It should be noted that the accuracy of an attribution is dependent upon gauging the objective qualities of what the person experienced; it is made on the basis of the attribution of certain properties to an object (Heider, 1958, p.169). 
Fourth, it must be recognized that a given effect may be interpreted in a number of ways. To make certain that there is a valid attribution, the NDEr will discount the least probable cause. We apply the discounting principle cited by Kelley (1973) to support this argument: "The role of a given cause in producing a given effect is discounted if other plausible causes are also present" (p. 113).

Fifth, when causal attributions derived from NDEs are associated with an explicitly communicated purpose, their effects can be demonstrated in a post near-death context (distinctiveness). They can then be validated in functional existence (consistency) and the NDEr can then say, "I know that I know."

\section{Causal Schema}

In the analysis of the function of causal attributions the following factors must be considered (see Table 1):

\section{Levels and Sequences}

For every behavior, there is an antecedent cause and event relationship. It follows that the lack of a one-to-one correspondence between a given behavior and a single cause or intent makes multiple interpretations inevitable. The NDEr organizes events into a causal schema which may reflect several levels of attribution, each of which may constitute either a primary or secondary causal source. Emergent levels and sequences of causality can be categorized as single level (one cause to one effect) or multiple levels (several effects to many causes). On the other hand, a given effect (behavior) may or may not be directly related to a given cause; it may have more than one causal source. Therefore, for the purpose of this and subsequent research, the causal sequences are classified as direct (no intervening sources) or indirect (one or more intervening sources).

\section{Context}

The context provides the environment within which causal attributions occur. These are defined as intrapersonal (within the experi- 


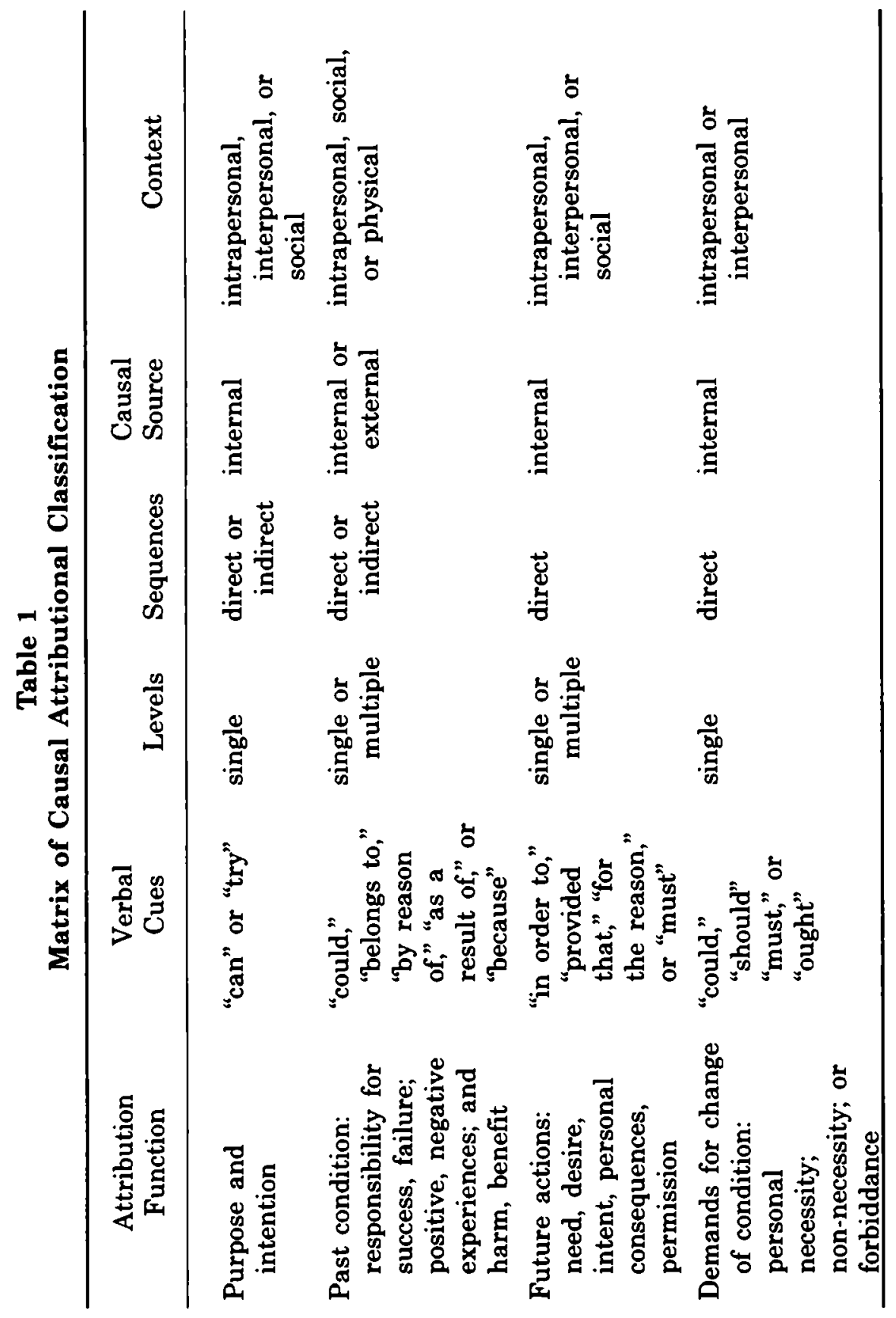


encer), interpersonal (between persons), social (within a social group or organization), or physical (the nonpersonal environment or setting).

\section{Interpreting the Meaning of the NDE}

\section{Resolution of Ambiguity}

The principle task of the NDEr in interpreting the meaning of the NDE is to resolve the ambiguities inherent in the situation. We use the following excerpt from an NDE account to illustrate the problem of resolving ambiguity. In this account, the NDEr is using an attribution of reason to understand the intent of her deceased aunt's appearance:

I saw my aunt, dressed in a red britches with a long red scarf around her neck. She was riding a white horse through a field of flowers in the direction of a beautiful old house, and 1 later won. dered why she appeared to me in this manner!

The problem in interpreting the meaning of the scene is to establish a hierarchy of primary, secondary, and tertiary causes. Why was the aunt dressed this way? Can the appearance of her clothing be attributed to the riding of the horse, or must it be attributed to causes antecedent to the riding of the horse? In the interview that followed, these questions were asked:

Q: How did you know it was your aunt?

A: I remember the red scarf well; she always wore it when she rode.

Q: Why was she going to the house?

A: I don't know, except that the house reminded me of our family farm.

Q: What is the meaning of it?

A: I think she was trying to tell me to go back to my roots.

Q: Was that her intent?

A: Yes!

\section{Identification of Causal Sources}

Interpretation of meaning entails finding a primary cause of the event. Where does it reside? It is important to consider causality 
from the standpoint of whether the cause resides within the individual or whether it is external to the self. In the following account, the identification of the hierarchy for primary, secondary, and tertiary causes of the experience is not clear. Is the event due to a direct intervention from the Lord, to the near-death experience, to the way the experiencer had felt about death, or to a combination of causes?

But since this experience, I don't fear death. Those feelings vanished. I don't feel bad at funerals anymore. I kind of rejoice in them, because I know what the dead person has been through. I believe that the Lord may have sent this experience to me because of the way I felt about death. (Moody, 1975, p. 95)

\section{Causal Interpretation}

Events do not just present themselves to the NDEr; they are the product of the NDEr's perception of reality (Schnaper and Panitz, 1990). The interpreter must ask, "What is the most probable cause?" The answer is typically derived from the subject's background of experience, systems of beliefs and values, and cultural conditioning.

\section{Context Reduction}

In interpreting the meaning of the NDE, it is important to identify the specific context within which the event occurred. We employ the technique of context reduction, a process wherein alternative referents (contexts) are reduced to the single most relevant one for the conveyance of meaning. This facilitates communicative accuracy. This process is demonstrated in the experiencer's encounter with the mystical presence of light referred to in Greyson's (1983) NDE Scale.

The mystical presence of light becomes a personage of light when the NDEr (that is, the attributor) places the presence in an interpersonal context (that is, when there is an exchange of information with the mystical presence).

When the semantic attributes of "love", "compassion" and "omniscience" are assigned to the personage of light during an interpersonal exchange, the personage of light is transposed into a personage of love and light.

Third, when perception of the personage of love and light is placed within the context of the NDEr's system of religious belief - if he or she is a Christian - and cultural frame of reference, the meaning 
is narrowed to a denotative set of attributes and the "personage" is transposed into the "Light of Christ."

Finally, when the Light of Christ is interpreted by the NDEr as possessing the totality of "Christ-like" attributes, the semantic label is applied and the personage becomes Jesus Christ.

\section{Relationship Between Code and the Belief System}

We have postulated that the belief system is a significant determinant of what is coded by the NDEr, and will therefore shape in. terpretation of the NDE. By code, we are referring to the verbal description of the account, including language usage and message content.

Brent Top and Wendy Top (1993) have suggested, however, that cultural differences are also an important determinant of how experiences are interpreted. They suggested that "near-death researchers are virtually unanimous in believing that the experiences are definitely shaded by cultural interpretation" (p. 165). However, the argument that belief systems are for the most part culturally determined may only partially account for differences in semantic and causal attribution. For example, in the following account the cultural determinant is somewhat obscure and the source of the belief system is not readily identifiable through the code system:

Q: You saw your pet in the heavenly place?

A: Yes, I saw our dog Sandy!

Q: By dog, do you mean pet?

A: Yes, pets are human beings to me.

Q: Why did he greet you and not some other pet?

A: Because he thinks like a human!

$\mathrm{Q}$ : Is this why you saw your pet, because he has a human-like spirit?

A: Of course! How else could he get there?

\section{Language Usage}

The interpretation of meaning is effected by the symbols used in codifying the experience. Language symbols represent concepts or classes of objects and functions comprising the things that are talked 
about in the external world. In the following statement, "I saw some spires in the distance. It reminded me of a church steeple, and I concluded that I must be approaching a church of some sort," the semantic concept of "churchness" is attributed to the object seen. But the conclusion that the building was a church is based upon an inferential attribution.

\section{Attributional Analysis}

For the purpose of this study, attributions are classified as causal (effect) and semantic (affect). Furthermore, in this study, we make a distinction between attributions to personal (internal) and environ. mental (external) sources, and the assignment of affective significance (quality) to an object, event or person. Fritz Heider (1958) stated:

In distinguishing between the attribution of an event to a direct causal source, and the attribution of a positive or negative quality to an experience, we do not mean that causal attribution and the affective significance do not influence each other. Actually, they are highly interdependent. (p. 170)

Events and conditions may be evaluated by the NDEr in terms of both their direct causal and affective significance. It is for this reason that both types of attributions may be expressed in the same verbal statement. For example, 'My mother's angelic appearance [semantic] together with what she told me [causal] convinced me that it was not time for me to go" contains both types of attributions. In the following discussion we will review how attributions function in in. terpreting the meanings of NDEs. The examples noted are derived from both published accounts of NDEs and interviews with NDErs.

\section{Causal Attribution}

Purpose and Intention. One of the most important aspects of attribution is purposeful action. Heider (1958) asserted that an action is perceived as purposeful when the words "can" and "try" are used to describe intention. In the example, "My mother said: 'I cannot keep you in the heavenly realm, for it is not your time to die,' " the con. 
cepts of "can" (in this example, "cannot") and an intention to "try" ("to keep you in the heavenly realm") imply purposeful action. It should be noted that when an explicit purpose is lacking, there is no direct causal attribution to conditions and persons. This is demonstrated in the following NDEr's account of the aftereffects of her NDE:

Sometimes life seems like a confusion [sic] string of events making no sense whatsoever. ... My growing years, my marriage, my career all contained troubling episodes. These episodes seemed without con. nection. I always wondered why ... why did these things happen as they did? . . . Were people "meant" to learn or see connections from their experiences? (Bubulka, 1992, p. 114)

In the following NDE account, the NDEr is grasping for a causal schema to understand the intentions of the persons encountered in the NDE. This is done by abstracting the relevant features of the situation:

I saw a group of men sitting around a table. They must have been the Judges of Israel, for there were twelve of them and they looked very wise. I concluded that they were there to judge me [intention] for [the reason that] the way I lived my life. Yet they seemed to be judging me [attribution to a person] with love and understanding.

Past Condition. Attributions link events to underlying conditions. To trace the cause and effect relationship, the NDEr must consider where the onus of responsibility lies. Is the success/failure of an action, the quality of an experience (positive and negative), or the harm/benefit attributable to environmental (external) or personal (in. ternal) sources? To what or whom must responsibility be attributed? We use Heider's concept of unit formation to delineate this process:

In the case of can, a unit is formed between the possibility of success or failure and person or environment. If the success belongs to a person, then the person is felt to be responsible for it; if it belongs to the environment, then the environment is held accountable. (1958, p. 89)

Was the boy able to climb the mountain because he was an expert mountain climber, or because the mountain was not very steep? In Russell Noyes's account of the aftereffects of the NDE, attributions may be assigned to both personal and environmental sources: 
As a result of their near death experiences [environmental sources], many reported greater aliveness ... in terms of invulnerability and of special importance or destiny. In addition, some described having received the special favor of God [personal source]. (1982, p. 263)

In the following NDE account, the change in attitude and behavior may be attributable to a combination of environmental and personal causes:

And it seems that the understanding I have of things now is so much better. I feel like this is because of what happened to me, because of the places I went and the things I saw in this experience. (Moody, 1975, p. 90)

In George Ritchie's denial of responsibility for his failure to see Jesus, he attributed the condition to unknown causal sources:

And suddenly I realized that there was a common denominator to all these scenes. ... Whether it was a physical appetite, an earthly concern, an absorption with self - whatever got in the way of His Light created the separation into which we stopped at death. (Ritchie and Sherrill, 1978, p. 67)

Future Actions. Causal attribution may be attributed to a future action including need, future condition, desire, permission and forbiddance: "I was told that I had to live my life in a loving way in order to return to the heavenly realm"; or "He pleaded to understand what he needed to do in order to see his father again." Raymond Moody's (1975) account of the Venerable Bede's (673 to 735 A.D.) "return from the dead" story provides an explicit example of the attributions of necessity, demand and future condition. Bede's guide through the spirit world told him he must return:

"You must now return to your body and live among men once more;
but, if you will weigh your actions with greater care and study to
keep your words and ways virtuous and simple, then when you die,
you too will win a home among the happy spirits that you see. ..."
When he told me this, I was most reluctant to return to my body;
for I was entranced by the pleasantness and beauty of the place I
could see and the company that I saw there. (Moody, 1977, p. 67)

To whom does one attribute a voluntary or involuntary decision? In the following statement, responsibility for an action is attributed to authority figures: "The judges told me that they had given me 
permission to visit the garden. It is what I wanted to do, and I was grateful to them."

Demands for Change of Condition. Direct or indirect demands are indicated in verbal accounts by the use of the grammatical forms of "ought," "should," and "must" to express changes of condition, necessity, non-necessity, and forbiddance.

If the statement "You ought to return to your family" is answered by the word "Why?", an underlying attribution of demand is made to other personal or nonpersonal sources. In the statement "You should go back because it isn't your time to die," a direct attribution is made. In this example, a demand related to causal conditions is shown by the use of the grammatical forms "for," "because," and "why."

However, in the statement "I concluded that my husband wanted me to come back inasmuch as he would have to raise the children alone," an attribution is made indirectly to the self; the self is a secondary source of the conclusion.

The use of the verb form "must" will generate both positive and negative attributions. In the statement " $\mathrm{My}$ guardian angel told me that I must return to the earth because I was needed," the angel assigns an attribution of necessity to a need, but in the statement "You must not see the man when you return to earth because he is trying to destroy you," an attribution of forbiddance is assigned. On the other hand, in the statement "You need not return at once, because you are not needed," an attribution of nonnecessity is generated.

\section{Semantic Attribution}

Semantic attribution is the process wherein the subject assigns meaning to perceptions and experiences through the use of linguistic symbols (see Table 2). The term semantics refers to the relationship between an external world of objects, events, and the language system used to describe them.

The study of semantics is traditionally approached from the standpoint of meaning. Words are labels for objects and concepts existent in the nonlinguistic world. Thus semantic attribution must consider word and sentence meaning, including semantic functions and relations, and an analysis of the speech act itself. 


\section{Attributions of Affective Significance}

The affective significance of an event relates to dynamics underlying the rationalization of self-behavior and the assignment of responsibility for outcomes. Affective or connotative meanings are derivatives of affective attributions.

Affective Belief. The self is the causal source of an affective belief. The function of this attribution is to rationalize conditions, circum. stances, and self-behavior.

Heider summarized the importance of belief as follows: "It is what he [the NDEr] believes to be true that directly influences his reaction, the actuality having psychological significance only indirectly if at all" (1958, p. 173). This is evident in the following account:

I believed that I [attribution to the self] was surrounded by evil beings and I knew that I had to oppose them because I could see into their hearts and could understand their motives. I concluded that my transcendent wisdom was not appreciated because my de. tractors believed only what they were told.

Changes in belief systems are attributable more to changes occurring within the self than to external sources. Edward Hoffman's recorded testimony from a 62.year-old woman demonstrates that subjective attributions may occur as a function of the changes in affective feeling state within the self. In this testimony, the NDEr attributed God's presence to a feeling of joy [primary attribution] and her resultant belief in God to the manifestation of his presence [secondary attribution] within her:

One spring day, when I was five years old, I was visiting my grandmother and playing in her backyard. She had a lovely rose garden that she carefully tended. I sat on the grass and played near it, and then decided to walk over and look more closely at the roses.

As I did so, I suddenly felt God's presence in an almost over. powering way. The trigger could partly have been the sheer beauty of the roses [attribution of pleasure and feeling], but something else must have lifted my being into a new realm of awareness [attribution to an inanimate object]. The sensation probably lasted only a few minutes at most. But as a result I became a lifelong believer in God. (Hoffman, 1992, p. 46)

Connotation. Connotation generates subjective meanings and definitions. These may be described in terms of how the attributor in- 
Table 2

Matrix of Semantic Attributional Classification

\begin{tabular}{|c|c|c|c|}
\hline Type & $\begin{array}{c}\text { Attribute } \\
\text { of }\end{array}$ & $\begin{array}{l}\text { Assign- } \\
\text { ment } \\
\text { to }\end{array}$ & $\begin{array}{l}\text { Attributional } \\
\text { Function }\end{array}$ \\
\hline \multirow{3}{*}{$\begin{array}{l}\text { Affective } \\
\text { significance: } \\
\text { subjective } \\
\text { assignment of } \\
\text { meaning } \\
\text { to events and } \\
\text { experiences; } \\
\text { rationalization of } \\
\text { self-behaviors } \\
\text { through the use of } \\
\text { affective } \\
\text { attributions }\end{array}$} & $\begin{array}{l}\text { Affective } \\
\text { belief }\end{array}$ & The self & $\begin{array}{l}\text { Rationalization of self- } \\
\text { behaviors; } \\
\text { modifications in the } \\
\text { structure on the basis } \\
\text { of subjective belief }\end{array}$ \\
\hline & Connotation & $\begin{array}{l}\text { The self or } \\
\text { the } \\
\text { environment }\end{array}$ & $\begin{array}{l}\text { Assignment of } \\
\text { subjective meaning } \\
\text { and definitions to } \\
\text { objects, concepts, and } \\
\text { experiences }\end{array}$ \\
\hline & $\begin{array}{l}\text { Feeling } \\
\text { states }\end{array}$ & $\begin{array}{l}\text { The self or } \\
\text { another } \\
\text { person }\end{array}$ & $\begin{array}{l}\text { Changes in feeling } \\
\text { states attributed to the } \\
\text { self and others' } \\
\text { feelings of sorrow, joy, } \\
\text { and pleasure }\end{array}$ \\
\hline \multirow[t]{3}{*}{$\begin{array}{l}\text { Valuative } \\
\text { attributions: } \\
\text { placement of } \\
\text { qualitative and } \\
\text { quantitative } \\
\text { constraints on } \\
\text { objects, persons, } \\
\text { and conditions }\end{array}$} & $\begin{array}{l}\text { Positive } \\
\text { and } \\
\text { negative } \\
\text { value }\end{array}$ & $\begin{array}{l}\text { Objects, } \\
\text { conditions, } \\
\text { and persons }\end{array}$ & $\begin{array}{l}\text { Acceptance or rejection } \\
\text { of persons or objects } \\
\text { based upon } \\
\text { comparisons of } \\
\text { qualitative value; } \\
\text { assigns positive or } \\
\text { negative attributes }\end{array}$ \\
\hline & $\begin{array}{l}\text { Absolute } \\
\text { value }\end{array}$ & $\begin{array}{l}\text { Objects, } \\
\text { conditions, } \\
\text { and persons }\end{array}$ & $\begin{array}{l}\text { Assigns unique } \\
\text { qualitative and } \\
\text { quantitative attributes } \\
\text { to persons, objects, or } \\
\text { conditions }\end{array}$ \\
\hline & $\begin{array}{l}\text { Comparative } \\
\text { value }\end{array}$ & $\begin{array}{l}\text { Objects, } \\
\text { conditions, } \\
\text { and persons }\end{array}$ & $\begin{array}{l}\text { Assigns meaning to } \\
\text { others' comparative } \\
\text { attributes; typically } \\
\text { not present in prior or } \\
\text { past experiences }\end{array}$ \\
\hline
\end{tabular}


terprets an experience. The following account demonstrates how a stereotypical definition emerges as a function of belief and cultural conditioning. In this account, the identity of a personage - Jesus Christ - is attributed to nonverbal cues, likeness to a well known stereotypical portrayal of Jesus Christ:

An oncoming vehicle slid over three lanes to hit us head on. . . I looked down upon the accident scene. . . . A hand touched mine, and I turned to see where the peace and serenity and blissful feeling was coming from ... and there was Jesus Christ - I mean the way he is made out to be in all the paintings. (Greyson and Bush, 1992, p. 105)

Feeling States. "Why do I feel joy?" "What or who is responsible?" When a person experiences joy in interacting with an object, and sadness when the object is removed, the object becomes the cause of the enjoyment [attribution to an object]. The principle holds true when an attribution is made to the condition or a person, or an environment and its effect is often generalized to other objects, persons, or conditions. Attributions of feeling and the generalization process that often follows is illustrated in the following excerpt from the testimony of an NDEr:

A feeling of inexpressible joy emanated from the personage of light and I was filled with pleasure just being in His presence. But when he left me, I no longer felt the great exaltation, and my joy was gone. Now, after my NDE, I recapture some of that feeling when I see a picture of Christ or look out on a beautiful landscape. I know His presence is everywhere.

\section{Valuative Attributions}

Valuative attributions place qualitative and quantitative constraints on actions, objects, conditions, and concepts. In the following NDE account, valuative constraints are attributed to the NDEr's account of a visit to a garden:

The water was praising god for its life and joy. The overall effect seemed beyond the ability of any symphony or composer here. In comparison, our best music here would sound like a child playing a tin drum. We simply don't have the capacity to comprehend the vastness and strength of the music there, let alone begin to create it. ... That one experience, just the glimmer of a grander joy ... 
in being one with everything else, was so great that $I$ will cherish it forever. (Eadie and Taylor, 1993, pp. 80-81)

Valuative semantic attributions are also generated through the use of descriptors that modify objects, conditions, and concepts: "I will never forget the rose that I was. That one experience, just a glimmer of the grander joy that is available in the spirit world, in being one with everything else, was so great that I will cherish it forever" (Eadie and Taylor, 1993, p. 81).

Positive and Negative Value. Positive and negative value occur when a quality of an object, condition, or person is accepted or rejected. Consider the expression "I did not like the personage who met me in my dream." In that statement, a negative value attribution is made to a person. In the statement "I was surrounded by absolute truth," a positive value is attributed to the condition encompassing the NDEr.

Absolute Value. Finally, valuative semantic attributions are used to assign unique qualitative and quantitative attributes to persons, objects, and conditions. In the following account, the reader is asked to assume that a comparative judgment has been made: "My joy was absolutely full again! I felt God in the plant, in me, his love pouring into us. We were all one!" (Eadie and Taylor, 1933, p. 81). In the statement "I was surrounded by perfect love," a superlative attribution is used to describe a quality that could not be surpassed.

Comparative Value. A comparative value attribution assigns properties to objects, persons, and conditions assumed not to be present in prior existence. This attributional process is delineated in the following testimony: "The flowers were more beautiful than any I had seen on earth. I concluded that they were in the similitude of God's Love; they were the manifestation of purity as opposed to sin, and joy as opposed to sorrow."

\section{Summary}

We argue in this article that attribution theory is a worthwhile explanation for the descriptions of near-death phenomena. Attribution theory demonstrates how individuals cogitate the meaning of the NDE, and just as important, how these cogitations are commu. nicated by the NDEr to other people.

Two matrices are offered representing the relevant categories of causal and semantic attributions, respectively. In short, these matri- 
ces provide an overview of many levels, contexts, and sources of the attribution process. We have attempted to simplify, as much as possible, an extremely complex subject matter. To test whether these matrices have any external validity, we are currently conducting a series of studies that we expect to complete in the near future.

Numerous books and journal articles have been written on NDEs over the last several years, yet much of this literature is atheoretical in nature. By focusing on theory-based near-death research, the understanding of these phenomena will be enriched far beyond the anecdotal descriptions currently being published. This theory of attributing causality and semantic meaning to events, characters, and objects should provide heuristic value to interested individuals seeking an explanation of the NDE.

\section{References}

Bubulka, G. (1992). Beyond reality: A personal account of the near-death experience. Fresno, CA: Grace Bubulka.

Eadie, B. J., and Taylor, C. (1993). Embraced by the light. Placerville, CA: Gold Leaf Press.

Gabbard, G. O., and Twemlow, S. W. (1991). Do "near-death experiences" occur only near death? - Revisited. Journal of Near-Death Studies, 10, 41.47.

Greyson, B. (1983). The Near-Death Experience Scale: Construction, reliability and validity. Journal of Nervous and Mental Disease, 171, 369-375.

Greyson, B., and Bush, N. E. (1992). Distressing near-death experiences. Psychiatry, $55,95.110$.

Heider, F. (1958). The psychology of interpersonal relations. New York, NY: Wiley.

Hoffman, E. (1992). Visions of innocence: Spiritual and inspirational experiences of childhood. Boston, MA: Shambhala.

Irwin, H. J., and Bramwell, B. A. (1988). The devil in heaven: A near-death experience with both positive and negative facets. Journal of Near-Death Studies, 7, 38.43.

Kelley, H. H. (1973). The process of causal attribution. American Psychologist, 28107. 128.

Lundahl, C. R., and Widdison, H. A. (1993). Social positions in the City of Light. Journal of Near-Death Studies, 13, 231.238.

Moody, R. A., Jr. (1975). Life after life. Covington, GA: Mockingbird.

Moody, R. A., Jr. (1977). Reflections on life after life. St. Simon's Island, GA: Mockingbird.

Noyes, R., Jr. (1982). The human experience of death or, what can we learn from near-death experiences? Omega, 13, 251-259.

Ritchie, G. G., and Sherrill, E. (1978). Return from tomorrow. Waco, TX: Chosen Books.

Roberts, G. A., and Owen, J. H. (1988). The near-death experience. British Journal of Psychiatry, 153, 607-617.

Ross, L. M., and Pollio, H. R. (1991). Metaphors of death: A thematic analysis of personal meanings. Omega, 23, 291-307.

Schnaper, N., and Panitz, H. L. (1990). Near-death experiences: Perception is reality. Journal of Near-Death Studies, 9, 97-104. 
Sutherland, C. (1990). Near-death experience by proxy: A case study. Journal of NearDeath Studies, 8, 241.251.

Top, B., and Top, W. (1993). Beyond death's door. Salt Lake City, UT. Bookcraft. 